\section{JOURNAL OF THE SOUTH AFRICAN} INSTITUTION OF CIVIL ENGINEERING ISSN 1021-2019

Vol 59 No 3, September 2017, Pages 2-10, Paper 1568

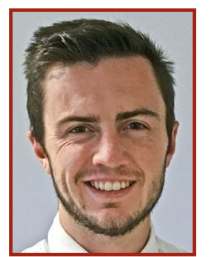

PAUL VORSTER studied at the University of Pretoria where he obtained a BEng degree in Civil Engineering. He completed his BEng (Hons) in Geotechnical Engineering in 2014 at the same university, and is currently employed in the Railway Division at GIBB (Pty) Ltd.

Contact details:

Railway Engineering Division

GIBB (Pty) Ltd

Woodmead North Office Park

54 Maxwell Drive

Woodmead 2191

South Africa

$\mathrm{T}:+27115194600$

E: pvorster@gibb.co.za

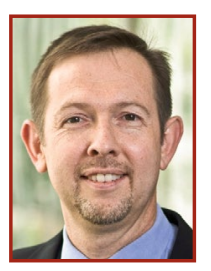

PROF HANNES GRÄBE Pr Eng, FSAICE, is a civil engineer with experience in the fields of track technology, geotechnology, advanced laboratory testing, field investigations, maintenance models and numerical analysis of track structures. He is currently employed by the University of Pretoria as Associate Professor: Transnet Freight Rail Chair in Railway

Engineering, where he lectures under- and post-graduate courses in railway engineering. He is also responsible for railway research, as well as for

continuing professional development in the form of short courses presented to industry.

\section{Contact details:}

Transnet Freight Rail Chair in Railway Engineering

Department of Civil Engineering

University of Pretoria

Pretoria 0001

South Africa

$\mathrm{T}:+27124204723$

E: hannes.grabe@up.ac.za

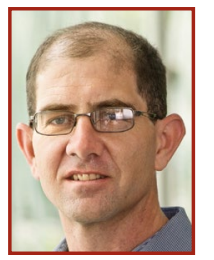

PROF SW JACOBSZ Pr Eng, MSAICE, graduated with an MEng degree in Civil Engineering from the University of Pretoria in 1996 and a PhD from the University of Cambridge in 2002. He is Associate Professor in the Department of Civil Engineering at the University of Pretoria. His research interests include physical modelling of problems in the geotechnical centrifuge. geotechnical and soil-structure interaction

\section{Contact details:}

Department of Civil Engineering

University of Pretoria

Pretoria 0001

South Africa

T: +27124203124

E: sw.jacobsz@up.ac.za

\title{
Centrifuge modelling of railway embankments under static and cyclic loading
}

\author{
P Vorster, P J Gräbe S W Jacobsz
}

With past embankment failures on the heavy haul coal export railway line between Ermelo and Richards Bay in South Africa, a study was conducted focusing on the modelling of embankments in a geotechnical centrifuge. This was done in order to investigate the influence of static and cyclic loading on settlement, and to evaluate the potential failure of the embankment under the loading conditions. The effect that moisture has on the slope stability was also investigated. A suitable loading system was developed that could be used to apply static and cyclic loading to a model embankment in the centrifuge. Embankment models representing a standard slope and using one material type with varying moisture content were built and tested in the centrifuge. Clayey sand material was sampled from one of the sites where a failure occurred on the coal line and was used for the tests. The loading system simulated the loading created by a heavy haul coal train with a $26 \mathrm{t}$ per axle load along the length of an embankment. The results from the tests conducted in the geotechnical centrifuge indicated that settlement resulting from the cyclic loading was on average $67 \%$ higher than that of the static loading when considering loaded time. It was observed that the tests with increased moisture content exhibited significantly reduced stability. A completely developed slip surface failure was not observed. However, cracks formed at the crest of the embankment along its length, which indicated a downward shift of material. The research therefore concluded that cyclic loading on railway embankments increases permanent vertical settlement of the embankment compared to static loading. As the moisture content was increased for the different tests, there was a clear increase in crack development at the crest of the embankment along its length.

\section{INTRODUCTION}

The failure of a railway embankment can result in large financial losses if the line has to be closed for remedial measures, rehabilitation or if a derailment occurs. The design of embankments is usually done with slope stability analysis methods of slices (Selig \& Waters 1994; Li et al 2016). The analysis is based on a combined factor of safety defined as the ratio of available shear strength to the shear strength that has to be mobilised to maintain the condition of limit equilibrium. In the case of railway embankments, a uniformly distributed load is applied over a central ballast width of the embankment to represent the load induced by the train. This, however, represents a static load and does not incorporate the effect of cyclic loading.

Physical modelling in a centrifuge is a powerful tool available to geotechnical engineers. It allows the study of complex design problems using geotechnical materials to create a more realistic representation of the stresses in the soil (Taylor 1995). The main objective of this study was to investigate the influence of static versus cyclic loading on railway embankments by testing models in the geotechnical centrifuge. This was done to investigate the failure mechanisms and the settlements associated respectively with static and cyclic loading. The effect of moisture on the stability of the slope was also investigated.

Furthermore, triaxial tests were conducted and soil moisture characteristic curves were determined to characterise the material used in the model study, to enable limit equilibrium stability analyses to be carried out for comparison with the observations from the centrifuge tests.

\section{BACKGROUND}

The investigation was based on embankments of the heavy haul coal export railway line between Ermelo and Richards Bay in South Africa. As a result of the large demand for coal export through Richards Bay, the line currently carries heavy axle loads of 26 t/axle and long trains of 200 four-axle coal wagons per train. The tractive effort available for these long trains is a limiting factor and therefore the grade should be kept to a minimum. In order to do this, large embankments had to be built on the line. Numerous cases of slope failures were reported by Transnet during 2007 on the Ermelo Richards Bay line as a result of high rainfall. Shallow slip surface failures, as well as 
deep-seated failures, occurred (Lourens \& Maree 1997). The objective of the current research was to investigate whether the cyclic nature of load application affected the failure mode observed on the embankments.

\section{Failure mechanisms and design}

Railway embankments can fail through several ways, namely:

- Embankment foundation failure, also known as massive shear failure

- Wedge failure

- Embankment slope failure.

Massive shear failure occurs as a result of unbalanced forces in the substructure of the railway line (Selig \& Waters 1994). The wedge failure mechanism occurs when a shear occurs between the embankment base and subgrade. Embankment slope failure involves the failure of the embankment slope through slip surfaces that are developed within the slope of the embankment.

Shallow slip surfaces are predominantly associated with the top $1.0-1.5 \mathrm{~m}$ layer of soil that experiences major seasonal fluctuations in pore pressure. The failure can be attributed to the advance of the wetting front and the reduction of the shear strength of the soil as a result of the decrease in matric suction in the unsaturated soil, i.e. the negative pore water pressures (Fredlund \& Rahardjo 1993; Rahardjo et al 1995). Rainfall and seasonal changes can have a significant effect on the matric suction in the soil.

\section{Material characteristics}

The microstructure of fine-grained soils is complex and is influenced, amongst other aspects, by the amount and type of clay in the soil (Gunn et al 2009). The Atterberg limits were introduced to describe how the moisture content affected plasticity and strength of fine-grained soils. A fine-grained soil with a moisture content at the liquid limit will have a shear strength of approximately $1 \mathrm{kPa}$ and will have the behaviour of a liquid. The plastic limit is described by the moisture content at which the soil has a shear strength of approximately $100 \mathrm{kPa}$ and will behave like a plastically deformable solid (Blackall 1952; Gunn et al 2009). The total stress acting on a soil mass can be considered as an external stress, and could either be due to a surcharge load or the self-weight of the soil. The pore pressure in saturated soils is usually positive and isotropic, whereas the pore pressure in unsaturated soils is generally negative. The effect that pore pressure has on the total stress in an unsaturated state depends on the degree of saturation and the pore size distribution (Lu \& Likos 2004). Unsaturated residual soils tend to experience high matric suctions during dry periods, which result in

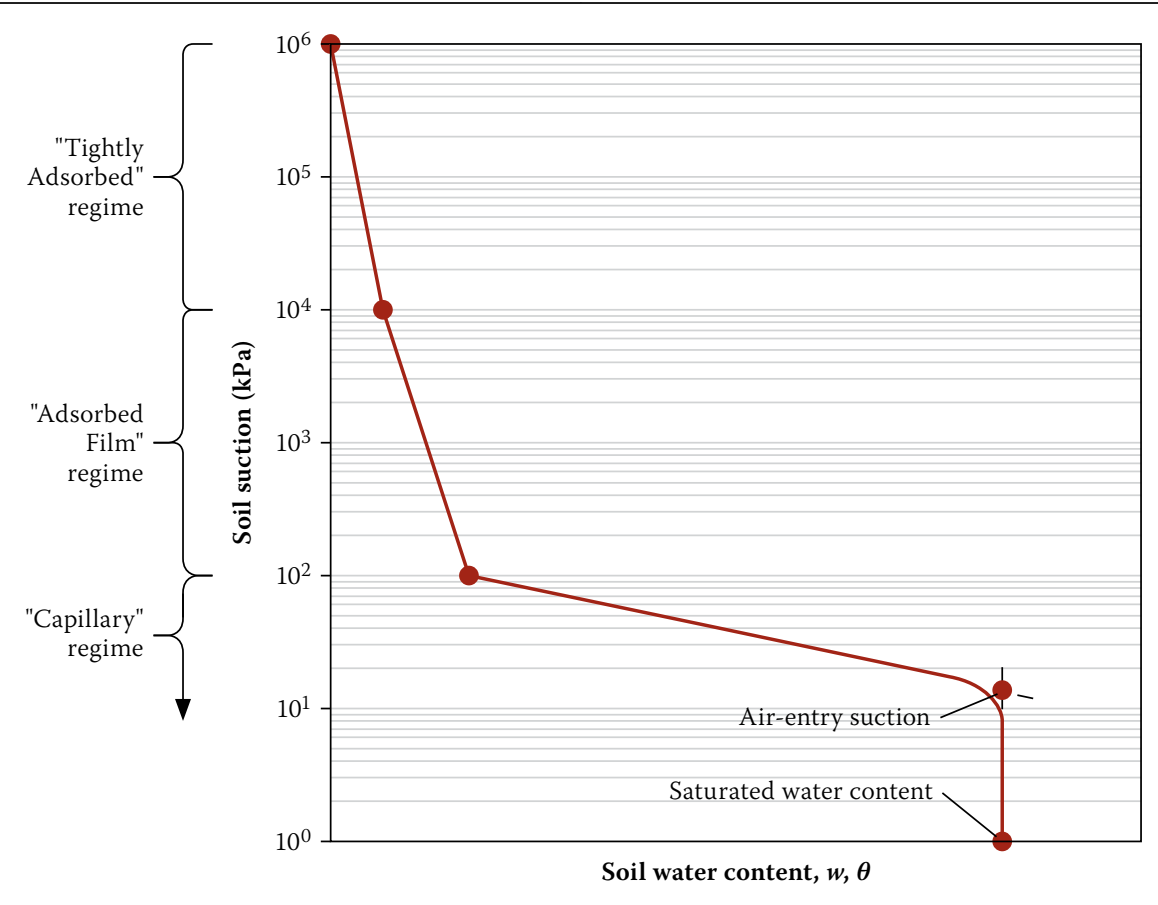

Figure 1 McQueen and Miller's (1974) conceptual model for an SWCC

an increase in shear strength of the residual soil (Rahardjo et al 2005). Extended wet periods may result in sufficient infiltration into the slope to decrease the matric suction in the soil. The additional shear strength provided by the suction is therefore reduced and a shallow landslide can be triggered (Fredlund \& Rahardjo 1993; Rahardjo et al 1995).

The relationship between the soil suction and the soil-water content is described by the soil water characteristic curve (SWCC). The shape of the SWCC is influenced by material properties such as the pore size distribution, grain size distribution, density, organic material content, clay content and mineralogy which affect the pore water retention behaviour (McQueen \& Miller 1974). Figure 1 shows an idealised SWCC. It can be simplified to three straight line segments on a semilogarithmic plot of suction versus moisture content ranging from zero to fully saturated.

The effect of long-term loading has become more important with the rise in whole-life costs for railway infrastructure. This means that the effect of cyclic loading has to be assessed for a new rail track in order to estimate the lifespan of the foundation and replacement thereof (Gräbe \& Clayton 2009). Vertical deformation from progressively developing shear strain is one of the results of repeated wheel loads. This is because the vertical stress during the loaded state is greater than the horizontal stress. The progressive volume change under repeated wheel loads that causes this vertical deformation can be summarised as a result of the following reasons (Selig \& Waters 1994; Li et al 2016):

- Particle rearrangement to form a more dense structure
Particle breakage causing smaller particles to move into voids

- Cyclic mobility.

Cyclic mobility refers to a decrease in volume of the soil under repeated loading. This is a result of accumulated strains with an increase in pore pressure. The increase in pore pressure results in a reduction of effective confining stress and therefore an increase in soil deformation (Selig \& Waters 1994; Li et al 2016).

During geotechnical centrifuge testing, small-scale models are accelerated to many times earth's gravity in order to recreate the true stresses experienced by the full-scale prototype soil in the model (Taylor 1995). The limitations of centrifuge experiments are the difficulties in constructing models that accurately mimic the important details of the full-scale prototype and the loading conditions it will experience (Turner \& Schuster 1996).

The tests described in this paper were carried out using the Actidyn C67-4, 150 g-ton centrifuge at the University of Pretoria. The centrifuge has a radius of $3 \mathrm{~m}$ and a model platform measuring $0.8 \mathrm{~m} \mathrm{x} 1.0 \mathrm{~m}$ (Jacobsz et al 2014).

\section{EXPERIMENTAL WORK}

To investigate the influence of static and dynamic loading on the failure of railway embankments, different centrifuge models were built and instrumented. The material and design of the embankment model chosen for the testing in the geotechnical centrifuge were based on the standard design specifications used for embankments on the 
heavy haul coal line where the slope failures occurred. The material was sampled at the Moolman slope failure site at kilometre 117, mast pole 14 ( $\mathrm{km} \mathrm{117/14)} \mathrm{on} \mathrm{Line} \mathrm{2,} \mathrm{close} \mathrm{to}$ Piet Retief. The standard embankment slope was designed at a 1:1.5 ratio. The top of the embankment allowed for a $5 \mathrm{~m}$ wide ballast section with $0.5 \mathrm{~m}$ shoulder on either side, as well as a $6 \mathrm{~m}$ wide service road. A schematic of the embankment cross-section is shown in Figure 2. The failures that occurred in the case studies were all on the upper $12 \mathrm{~m}$ of the embankments, and therefore it was decided to scale the embankment model accordingly.

The bulk earthworks of the embankments were designed to be compacted to 93\% Mod AASHTO density. The research conducted by Lourens and Maree (1997) showed that the density of problematic embankments on the coal line did not meet this level of compaction. A conservative value of $90 \%$ Mod AASHTO relative density was therefore selected for the embankment models. The material was compacted in $34 \mathrm{~mm}$ thick layers and scarified to create a good bond between the layers. The material was compacted to the required embankment height in the strongbox at the specified density; thereafter the required embankment shape was carved out.

Due to embankment cross-section symmetry, only one side of the embankment cross-section was modelled. This is seen as the worst-case scenario and represents a double-line embankment section on the coal line. The final cross-section used for the tests, with the simplified loading arrangement in place, is shown in Figure 3. The model was scaled at 1:50 and was therefore tested at an acceleration of $50 \mathrm{~g}$ in the geotechnical centrifuge.

\section{Loading methodology}

The loading methodology simulated the entire train load on the embankment for the duration that it takes the entire train to pass at a single location along the embankment. This meant that a low-frequency loading cycle was considered. The loading block was manufactured from a solid aluminium section that represented a uniformly distributed load exerted by a fully loaded $26 \mathrm{t}$ /axle wagon (total mass $104 \mathrm{t}$ ). The load application was controlled using a pneumatic piston, lifting and lowering the loading block onto the embankment at a specific loading cycle.

The time per loading cycle was calculated using the time it takes a train to pass a certain point on the embankment. This was calculated using the train speed of $80 \mathrm{~km} / \mathrm{h}$ and the train length of approximately $2.5 \mathrm{~km}$.

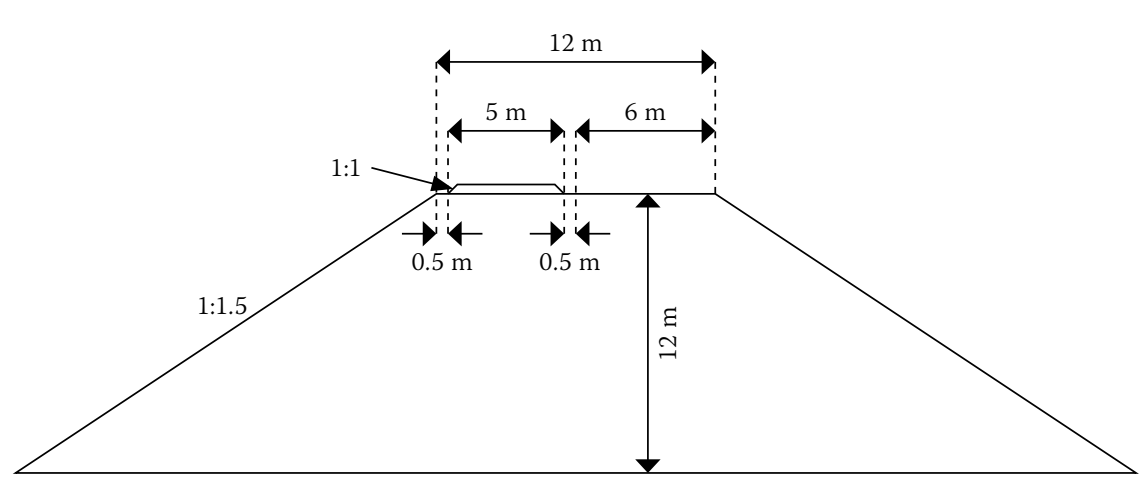

Figure 2 Standard embankment design cross-section, coal line (South Africa)

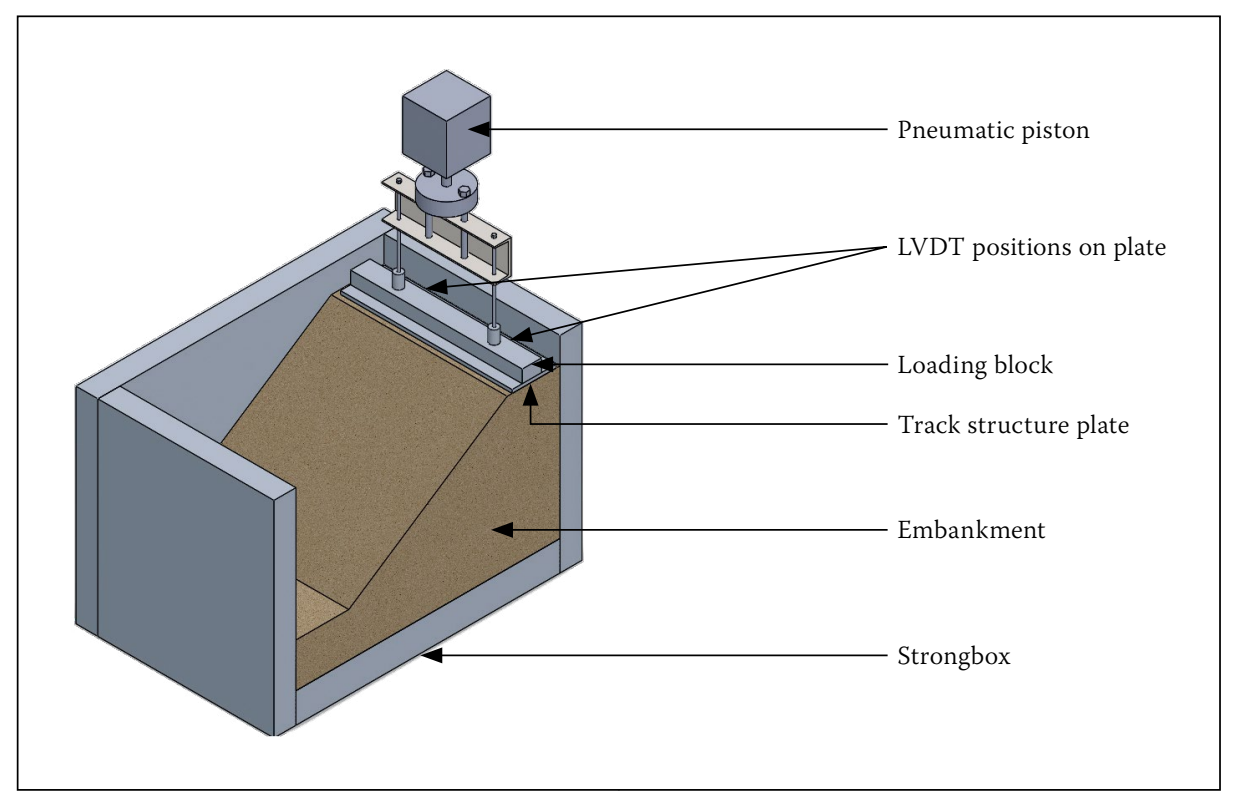

Figure 3 Final model assembly in strongbox

In order to calculate the loading time, the dynamic time scaling factor $t_{d y n}$ was used, which has a scaling factor of $1 / \mathrm{N}$ (where $\mathrm{N}$ is the model scale).

The approximate time taken by a train to pass over a section on an embankment at $80 \mathrm{~km} / \mathrm{h}$ is therefore 1.8 minutes. This corresponds to a loaded time of $2.16 \mathrm{~s}$ in the centrifuge. Taking into account the time for the pneumatic piston to lift and to lower the loading block, a cycle time of $20 \mathrm{~s}$ was chosen.

A separate loading plate was machined to replicate the loading created by the track structure on the embankment, i.e. the rails, sleepers and ballast. The weight from PY-sleepers (282 kg/sleeper) and $60 \mathrm{~kg} / \mathrm{m}$ rails was modelled assuming a conservative ballast density of $2000 \mathrm{~kg} / \mathrm{m}^{3}$.

Two loading methodologies were followed during the tests conducted, namely static loading and cyclic loading. A stabilisation period of one hour was allowed once the centrifuge reached $50 \mathrm{~g}$ acceleration before any loading was applied to the model. This was done to reduce the effect of initial settlement due to the self-weight of the embankment during the test. The static loading was applied for three hours after the stabilisation period.

\section{Centrifuge tests conducted}

The first four tests conducted in the study (A1 to A4) served as an iterative process to establish the turning point between a stable embankment model and an unstable embankment model in terms of soil moisture content. The final six tests (B1 to B6) were conducted at three moisture contents (two tests per moisture content) close to the established turning point. These tests were conducted at moisture contents of $21 \%, 22 \%$ and $23 \%$, with one test modelling the static loading scenario and the other the cyclic loading scenario.

\section{MATERIAL ANALYSIS}

Comparing the parameters of the material obtained from site to the parameters required by the S410 Earthworks Specification (Transnet 2006) revealed certain shortcomings. The comparison can be seen in Table 1 . The plasticity index of the 


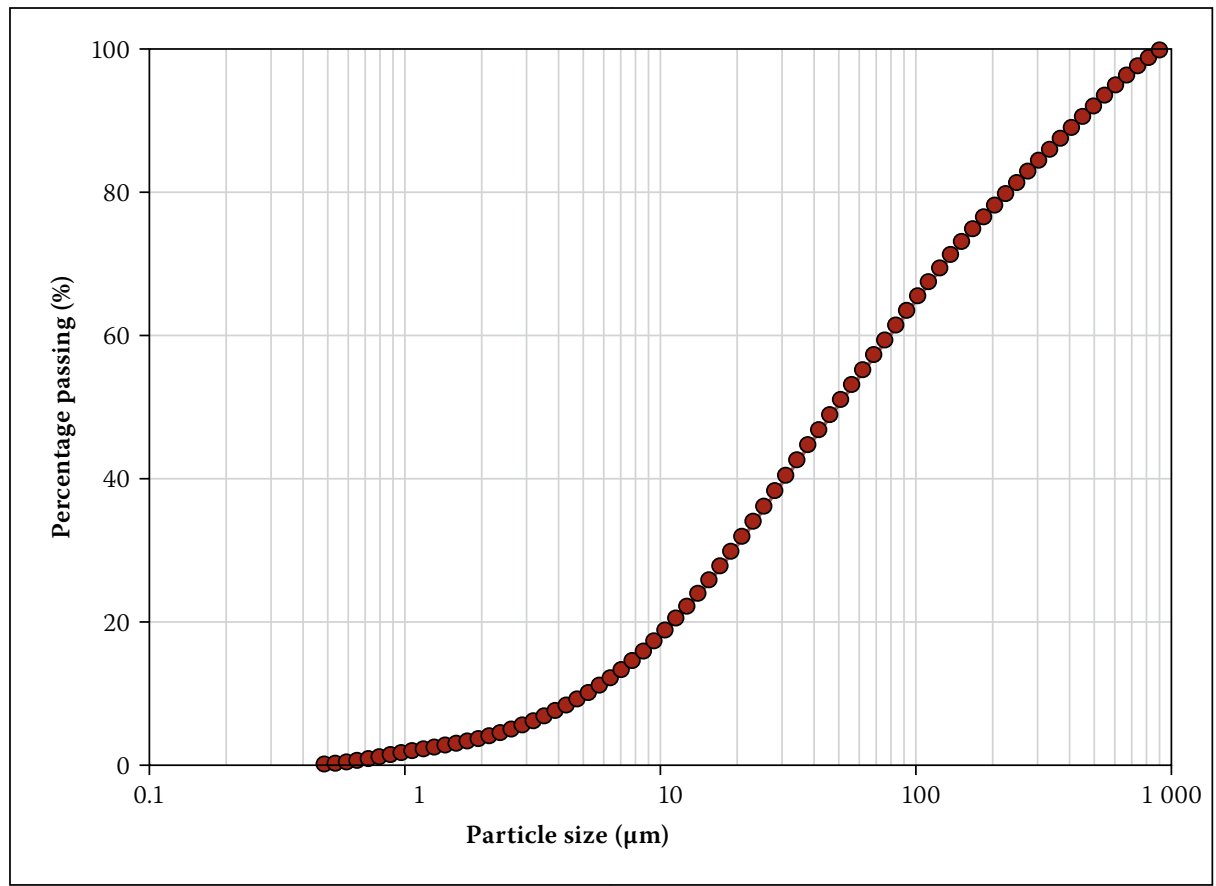

Figure 4 Sieve analysis of material used in the centrifuge and triaxial tests

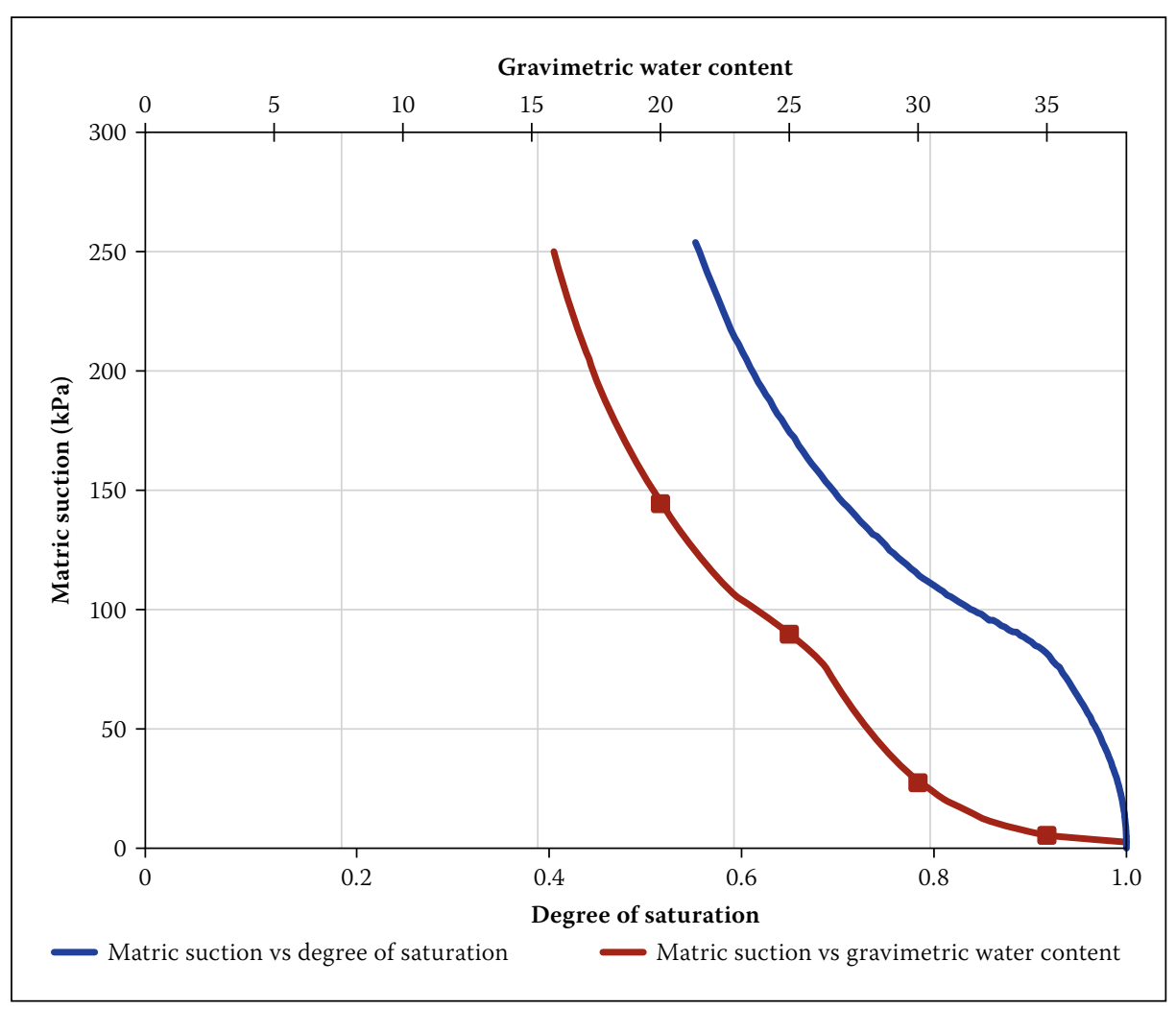

Figure $\mathbf{5}$ Soil moisture characteristic curves of the material used in the centrifuge and triaxial tests

Table 1 Material parameter comparison to the Transnet (2006) S410 specification for bulk earthworks

\begin{tabular}{|c|c|c|c|c|}
\hline \multicolumn{2}{|c|}{ Property description } & Sample 1 & Sample 2 & S410 \\
\hline \multirow{4}{*}{ Plasticity Index (\%) } & 17 & 17 & $<25$ \\
\hline & $\begin{array}{c}\text { \% Swell } \\
\text { (at 100\% Mod } \\
\text { AASHTO) }\end{array}$ & 1.3 & 4.1 & Maximum 2\% \\
\cline { 2 - 4 } & $90 \%$ & 1.7 & 0.8 & \multirow{2}{*}{$\begin{array}{c}\text { Minimum } \\
\text { strength after } \\
\text { compaction } \\
\text { (CBR) }=5\end{array}$} \\
\cline { 2 - 4 } $\begin{array}{c}\text { CBR (MSHTified } \\
\text { TMH1 A8 }\end{array}$ & $93 \%$ & 1.9 & 0.8 & \\
\cline { 2 - 4 } & $95 \%$ & 2.1 & 0.9 & \\
\cline { 2 - 4 } & $97 \%$ & 2.2 & 1.2 & \\
\cline { 2 - 4 } & $98 \%$ & 2.3 & 1.3 & \\
\hline
\end{tabular}

material was adequate for bulk earthworks, while the CBR results of the two samples taken on site were well below the required value. This could be due to the significant amount of mica observed in the material. Tubey and Bulman (1964) showed that the content of mica in the soil significantly affects the engineering properties, such as the plasticity index, compacted density and strength. Weinert (1980) also described micas as highly elastic minerals that influence the Atterberg limits, density and the compatibility of the material.

The particle size distribution of the material, generated using a Mastersizer (Malvern 2012), is presented in Figure 4. The Mastersizer provides a particle size distribution over the range from $0.02 \mu \mathrm{m}-2000 \mu \mathrm{m}$ by means of optical techniques. There was a small percentage of clay in the original material and a large amount of silt. The soil classified as a clayey sand (SC - Unified Classification). Only material smaller than $2.0 \mathrm{~mm}$ was used for the centrifuge testing.

Consolidated undrained triaxial tests were done to obtain the strength parameters of the material. Three samples were tested at effective stresses of 75, 150 and $250 \mathrm{kPa}$ respectively. The samples were prepared at a moisture content of $22 \%$ and a dry density of $1648 \mathrm{~kg} / \mathrm{m}^{3}$ (90\% Modified AASHTO). The friction angle and cohesion intercept obtained were $34^{\circ}$ and $0 \mathrm{kPa}$ respectively.

Drying tests were conducted on the material used for the centrifuge and triaxial tests to obtain the soil moisture characteristic curves. The graph of matric suction against the degree of saturation, as well as the matric suction against gravimetric water content, can be seen in Figure 5. The turning point in matric suction in Figure 5 is at the point where there is a sharp change in gradient. This point corresponds to a moisture content value of approximately $26 \%$ and a degree of saturation of $93 \%$ for this test. This can be identified as the air entry suction point. The bulk density of the material at this point is $1938 \mathrm{~kg} / \mathrm{m}^{3}$. The corresponding 90\% modified AASHTO bulk density at $93 \%$ degree of saturation is $2009 \mathrm{~kg} / \mathrm{m}^{3}$ with a moisture content of $22 \%$. This moisture content can therefore be taken as the turning point where there is a significant increase in suctions and therefore strength during drying. When the moisture content of a soil increases to above the moisture content corresponding to the air entry value, the soil would be expected to become saturated, with a subsequent decrease in pore water suctions, and hence a decrease in the shear strength of the material. A decrease in the shear strength of the material will in turn result in an expected increase in settlement under loading. 


\section{Limit equilibrium analysis}

Matric suction plays an important role in the stability of slopes. Slope stability analyses using the Morgenstern-Price method of slices were carried out to assess the stability of a loaded versus unloaded embankment under various cohesion intercepts. The cohesion intercepts were assumed to represent matric suction values in the material, as discussed below. The material properties used in the analyses were obtained from the triaxial tests and the soil moisture characteristic curve.

The material properties used in the analyses were as follows:

- Unit weight: $19.6 \mathrm{kN} / \mathrm{m}^{3}$

- Friction angle: $34^{\circ}$

- Cohesion intercepts (modelling matric suction): $0 \mathrm{kPa}, 2 \mathrm{kPa}, 5 \mathrm{kPa}, 10 \mathrm{kPa}$ and $80 \mathrm{kPa}$

- Loading $=38 \mathrm{kN} / \mathrm{m}^{2}$

It was decided to perform the analyses up to $80 \mathrm{kPa}$ suction based on the results of the soil moisture characteristic curve. The matric suction at $22 \%$ moisture content was $116 \mathrm{kPa}$. To convert this to additional shear strength given by cohesion, the following formula/calculation was used:

$\tau=(\sigma-u) \tan \phi^{\prime}$

The additional shear strength as a result of the suction is given by: $-u * \tan \phi$ '.

Emphasis is placed on the major effect that suction has on embankment stability. Suction provides apparent cohesion which increases the shear strength of the soil.

The comparison between the loaded and unloaded scenarios is plotted in Figure 6.

Comparing the factors of safety for all the analyses, it is evident that the loaded conditions have lower factors of safety and therefore a higher likelihood of failure. In this analysis it is assumed that the cohesion is constant throughout the entire model, which is not necessarily the case in reality. It can be seen that cohesion, and therefore matric suction, has an important stabilising effect on slope stability.

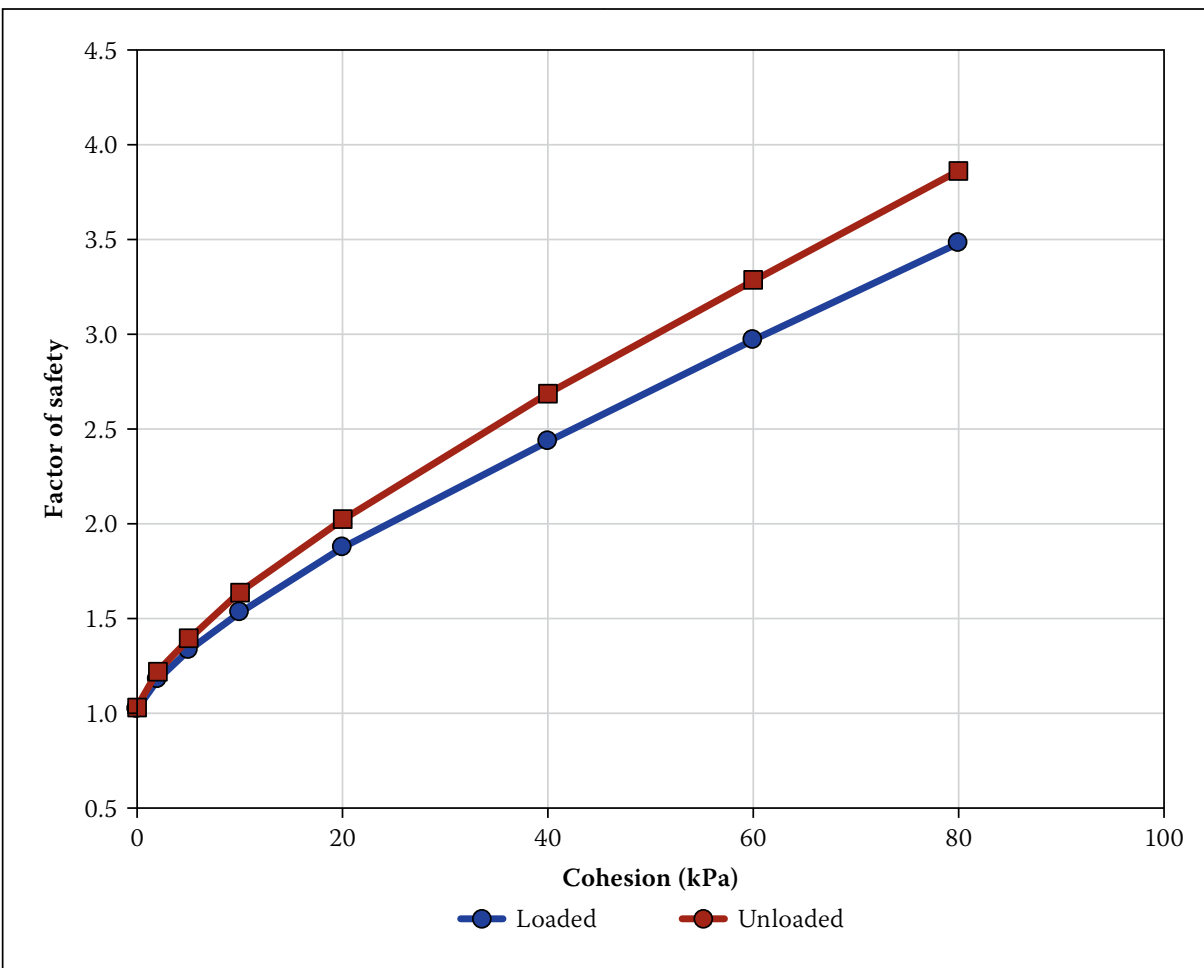

Figure 6 Factor of safety values obtained for different suctions for loaded and unloaded scenarios

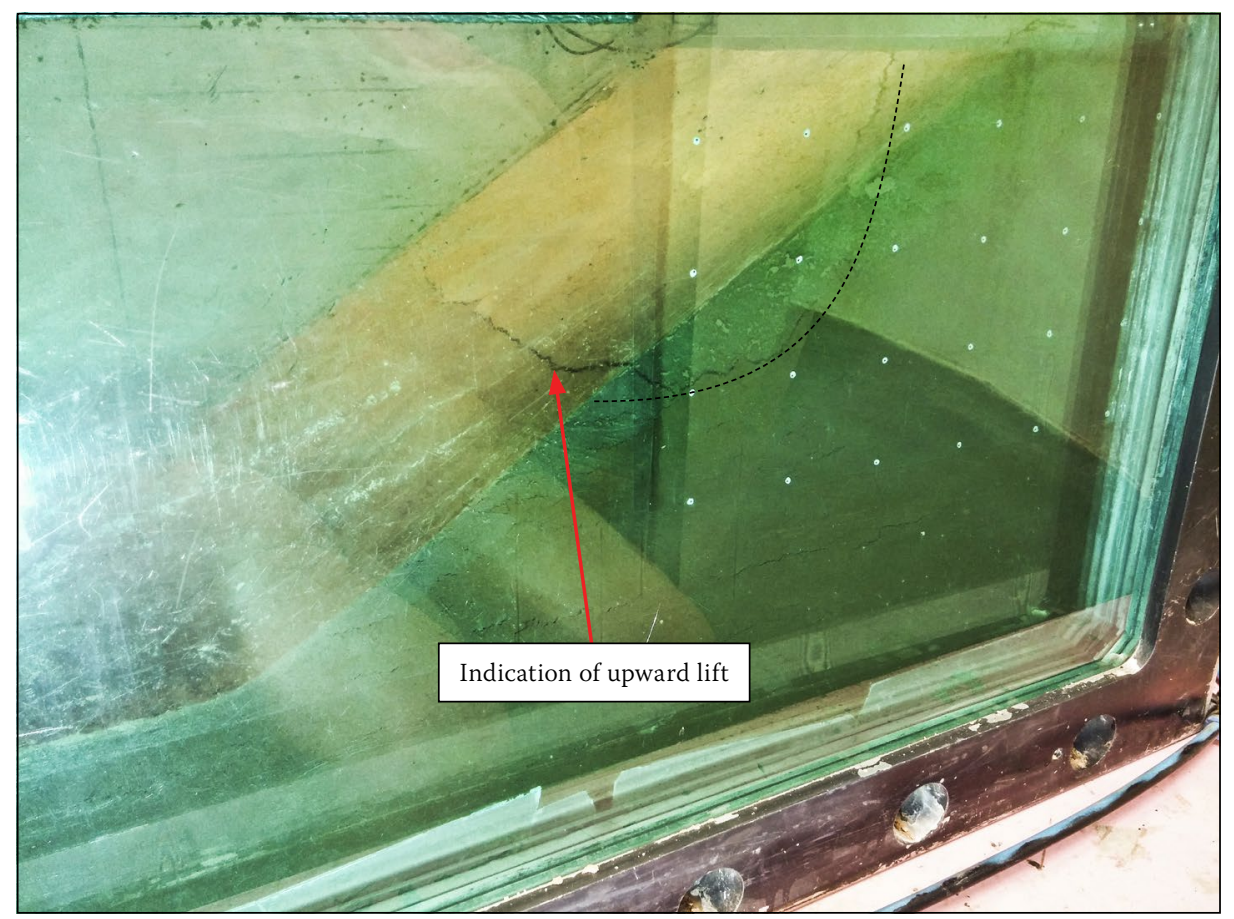

Figure 7 Circular slip-shaped crack which formed during Test B5 $(23.0 \%$ MC)

Table 2 Moisture content measured from samples after Test B1 to Test B6

\begin{tabular}{|c|c|c|c|c|c|c|}
\hline \multirow{2}{*}{$\begin{array}{l}\text { Position in } \\
\text { embankment }\end{array}$} & \multicolumn{6}{|c|}{ Moisture content (\%) } \\
\hline & $\begin{array}{c}\text { Test B1 } \\
\text { static loading } \\
(\text { MC 21\%) }\end{array}$ & $\begin{array}{c}\text { Test B2 } \\
\text { cyclic loading } \\
(\mathrm{MC} 21 \%)\end{array}$ & $\begin{array}{c}\text { Test B3 } \\
\text { static loading } \\
\text { (MC 22\%) }\end{array}$ & $\begin{array}{c}\text { Test B4 } \\
\text { cyclic loading } \\
\text { (MC 22\%) }\end{array}$ & $\begin{array}{c}\text { Test B5 } \\
\text { static loading } \\
\text { (MC 23\%) }\end{array}$ & $\begin{array}{c}\text { Test B6 } \\
\text { cyclic loading } \\
\text { (MC 23\%) }\end{array}$ \\
\hline Top & 11.9 & 9.3 & 13.9 & 11.3 & 13.7 & 9.6 \\
\hline $50-100 \mathrm{~mm}$ & 19.1 & 18.3 & 20.7 & 18.9 & 20.3 & 18.8 \\
\hline $100-150 \mathrm{~mm}$ & 19.0 & 20.0 & 21.0 & 20.7 & 21.5 & 20.6 \\
\hline $150-200 \mathrm{~mm}$ & 19.8 & 19.6 & 20.8 & 21.5 & 21.8 & 21.2 \\
\hline Bottom $(240 \mathrm{~mm})$ & 20.7 & 18.7 & 21.7 & 20.9 & 20.8 & 21.9 \\
\hline
\end{tabular}




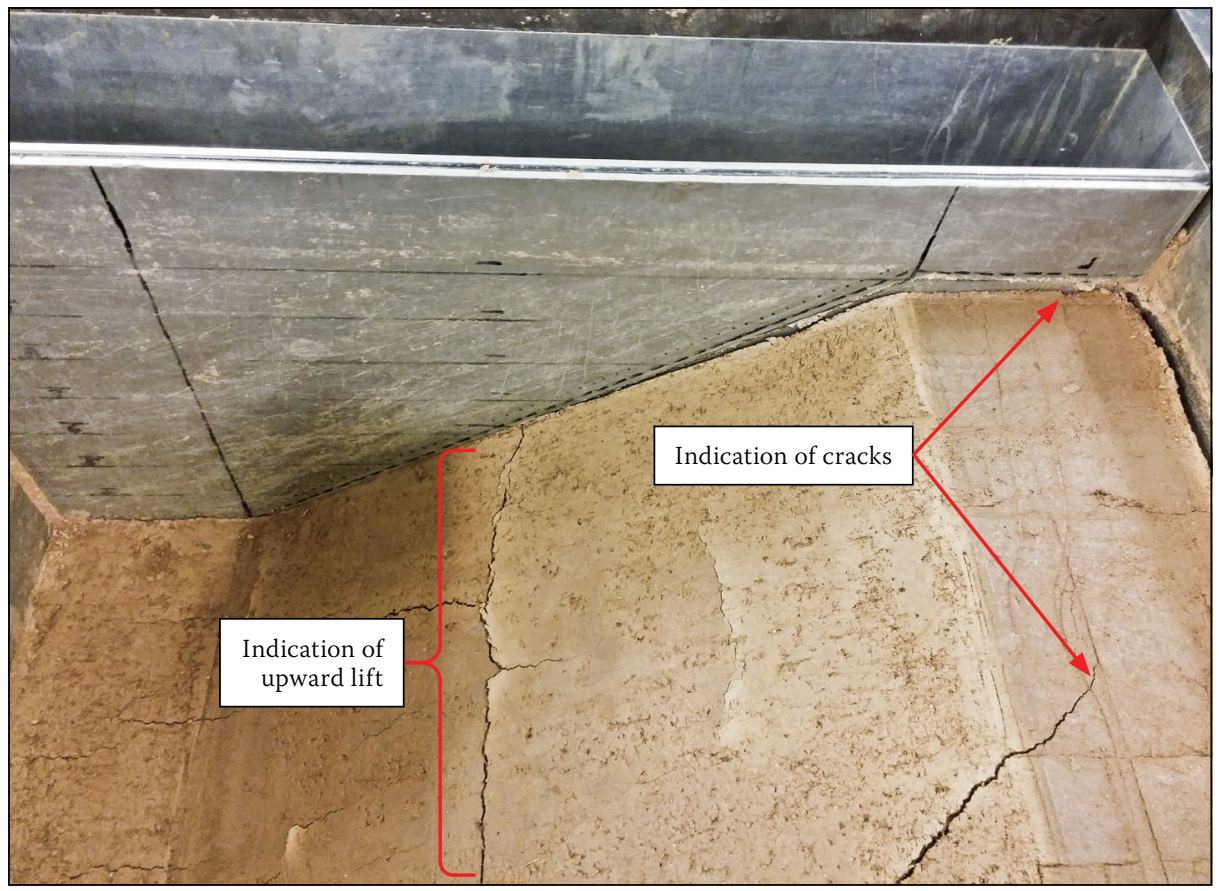

Figure 8: Indication of cracks created during Test B5 (23.0\% MC) joining at the top of the embankment

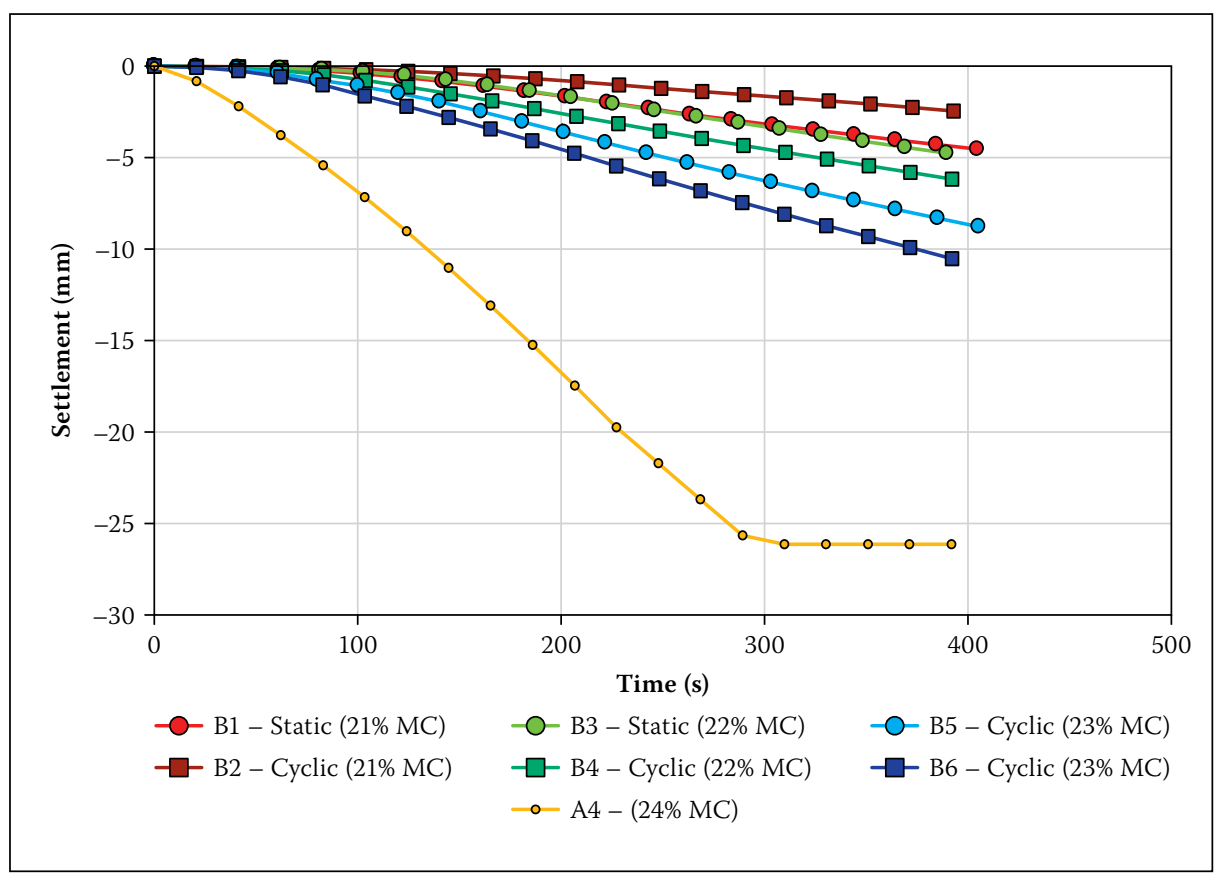

Figure 9: Settlement during centrifuge acceleration for Tests B1 to B6 and A4

\section{CENTRIFUGE TEST RESULTS}

Moisture content readings were taken at the end of the tests in order to demonstrate the effect of moisture loss during testing. The moisture contents were measured at defined depths in the embankment. The readings and depths are given in Table 2. The table shows that the top of the embankment dried out significantly during testing. The moisture content readings showed that on average, with the exception of the model surface, approximately $1 \%$ to $2 \%$ of the initial moisture was lost during model construction and testing. The drying of the material contributed to an increase in strength of the embankment as a result of an increase in matric suctions in the material. the soil and non-uniform settlement. The position of these cracks correlated relatively well with the location of critical slip surfaces from the limit equilibrium slope stability analysis conducted. The shallow slip surface calculated from the slope stability analysis also started at the crest of the embankment for both loaded and unloaded conditions, and corresponds with the formation of cracks at the crest of the embankment in the centrifuge tests before the loading started. The analyses conducted with higher cohesion intercepts showed deep-seated failures with larger factors of safety. This illustrates how cohesion in the soil, which can be used to represent matric suction, significantly affects slope stability. The SMCC showed that, for the moisture content range in the centrifuge tests $(21 \%-23 \%)$, there was a significant amount of suction present in the soil. The effect of the soil drying during the tests significantly increased the soil suction strength on the surface of the embankment model, thereby reducing the likelihood of a slope failure occurring.

The embankment settlement during the centrifuge acceleration to $50 \mathrm{~g}$ is shown for each test in Figure 9. The graph includes Test A4 conducted at $24 \%$ moisture content. It is evident that higher moisture contents were associated with higher settlement values, especially when comparing the settlement curves of the $23 \%$ and $24 \%$ moisture content samples. This can be seen as a turning point between a relatively stable slope and a slope that collapsed. It should also be noted that, for the tests with the same moisture contents, the settlements were not exactly the same. This could be due to variability in moisture throughout the embankment model, or variability in the compacted density.

A settlement comparison was made between the static loading and cyclic loading tests for the total test duration of three hours. The settlement comparison curves for the static and cyclic loading tests are shown in Figure 10. The tests at 21\% and $22 \%$ moisture content show similar settlements, with the cyclic settlements being somewhat larger than the static. The settlement curve for the cyclic loading test at $23 \%$ moisture content shows a $48 \%$ increase in settlement from the static loading settlement at 23\% moisture content. This significant increase in settlement for the cyclic loading test at $23 \%$ moisture content highlights the important effect that cyclic loading has on a material as the moisture content increases. The moisture content in question just exceeds the air entry point (estimated at approximately 22\%) when referring to the SMCC (see Figure 5). 
Further comparison between the static and cyclic loading was made by taking into account only the actual time that the load was in contact with the embankment during the cyclic loading tests. During the $20 \mathrm{~s}$ loading and unloading cycle, the embankment was under-loaded for approximately $2.5 \mathrm{~s}$ to $3.5 \mathrm{~s}$ only. In order to compare the settlement magnitude under cyclic and static loading for the duration that the embankment was physically loaded, a conservative value of $4 \mathrm{~s}$ of loading per $20 \mathrm{~s}$ cycle was chosen. The settlement curves for the cyclic loading tests were therefore shortened by a factor of 5 to produce comparable graphs with regard to the actual loaded time. Therefore, the $12 \mathrm{~h}$ settlement time of cyclic loading is compared to the $2.4 \mathrm{~h}$ settlement during the static loading test. Figure 11 shows the settlement curves for all tests plotted against the contact time.

The increase in the settlement difference between static and cyclic loading with regard to loaded time settlement shows an increase of $8.7 \%$ from $21 \%$ to $22 \%$ moisture content. However, a large settlement increase of 51\% is seen from $22 \%$ to $23 \%$ moisture content. This emphasises the effect that the moisture content of a soil has on its shear strength when the moisture content increases above the air entry value of the soil. At this level of saturation there is a definite decrease in pore water suctions, and hence a decrease in the shear strength of the material. The material showed a 93\% degree of saturation (at 22\% $\mathrm{MC}$ ), with a corresponding suction value of $75 \mathrm{kPa}$ obtained from the SMCC and a 97\% degree of saturation (at 23\% MC) where the corresponding suction value decreases significantly to $49 \mathrm{kPa}$.

To obtain a more accurate representation of the difference in settlement between the static and cyclic loading, when taking into account only the loaded time, the settlement that took place during the unloaded period of each cycle during the cyclic loading test was subtracted. This can be viewed as the settlement due to the self-weight of the embankment alone. Figure 12 shows the amount of accumulated settlement that took place during the loading period of each cycle and the amount of accumulated settlement that took place during the unloaded period of each cycle with the cyclic loading tests. The amount of settlement that took place during the unloaded period of the cyclic loading test was approximately $5 \%$ to $10 \%$ of the total settlement, despite the loaded period being only $2.5 \mathrm{~s}$ to $3.5 \mathrm{~s}$ of the $20 \mathrm{~s}$ loading cycle.

The final settlements for each testing phase in the geotechnical centrifuge are given in Figure 13. The graph shows a similar pattern for the different moisture contents

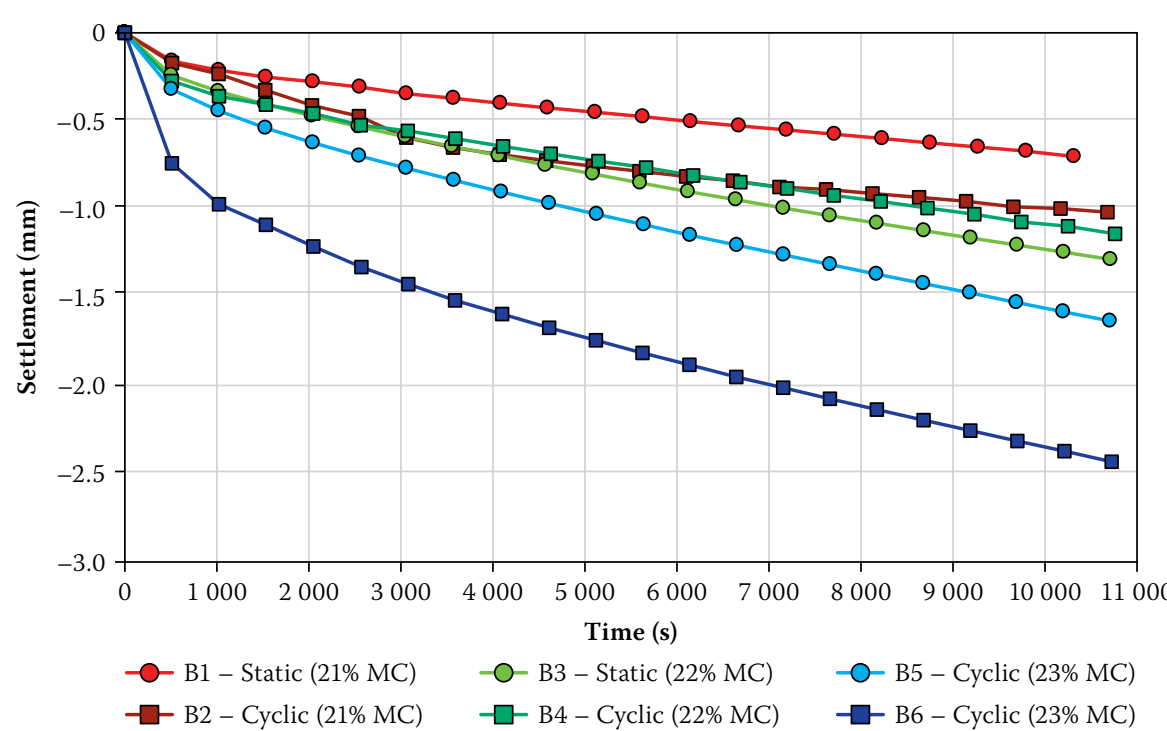

Figure 10: Settlement comparison curves between static and cyclic loading tests after 3 hours

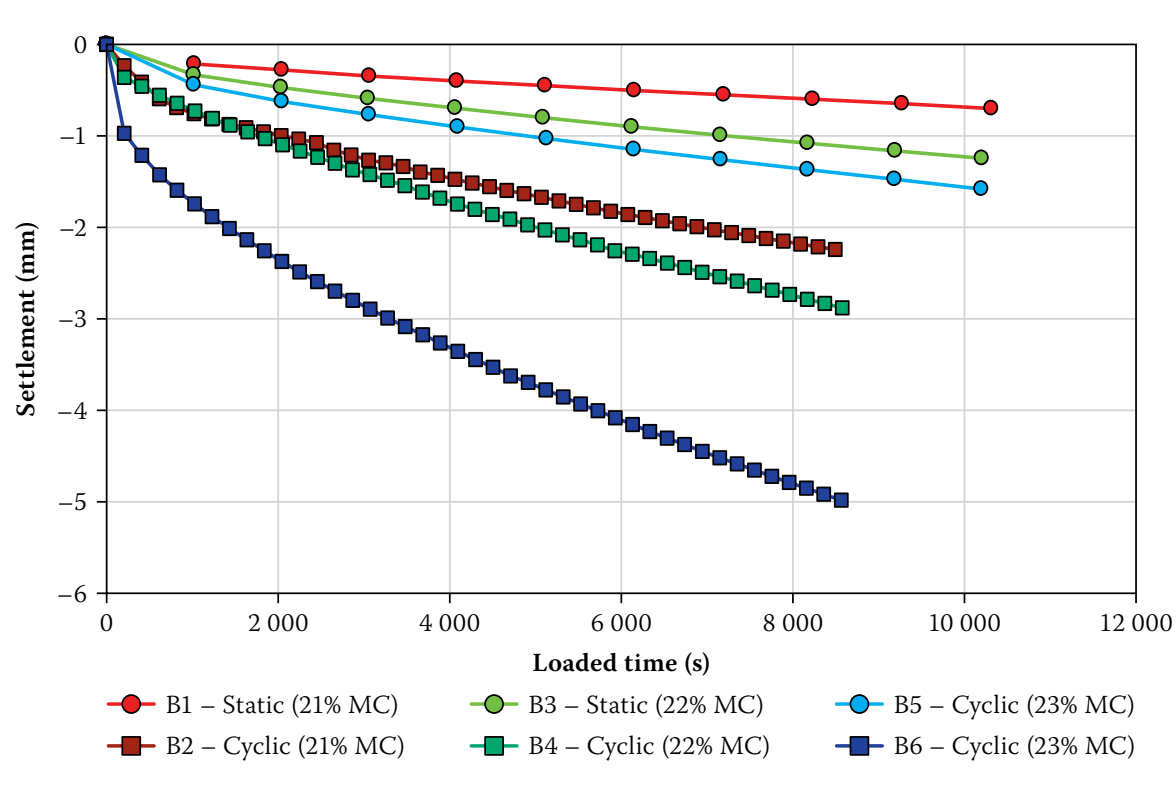

Figure 11: Settlement curves for all tests plotted against contact time

and a clear increase in settlement is visible as the moisture content increases above $22 \%$. It is evident that the most settlement occurs during the acceleration period of the centrifuge. This is to be expected, as the load on the embankment from self-weight increases fifty-fold during the acceleration from $1 \mathrm{~g}$ to $50 \mathrm{~g}$. A stabilisation period was added to the test procedure once an acceleration of $50 \mathrm{~g}$ had been reached to allow pore pressure to reach equilibrium prior to load application.

The settlement as a result of the cyclic loading was on average $67 \%$ higher $(70 \%$ at $21 \% \mathrm{MC}, 60 \%$ at $22 \% \mathrm{MC}$ and $70 \%$ at $23 \%$ $\mathrm{MC})$ than that under static loading when considering the contact time only. This can be attributed to continuous particle rearrangement during the cyclic loading process, as well as changes in the pore water pressures or suctions.

\section{CONCLUSIONS}

The conclusions from the static and cyclic loading tests on railway embankment modelling at $21 \%, 22 \%$ and $23 \%$ moisture contents in a geotechnical centrifuge are as follows: The moisture contents chosen were near the air entry value of the soil. Cyclic loading significantly increases the magnitude of the vertical settlement compared to that of static loading. It was observed that the increased moisture content reduced the stability of the embankment significantly. A complete slip surface failure was not observed, but significant cracks formed at the crest of the embankment along its length. The static and cyclic loading tests at $21 \%$ and $22 \%$ moisture content, as well as the static loading test at $23 \%$ moisture content, showed similar settlement curves with only minor increases in settlement, with an increase in moisture 


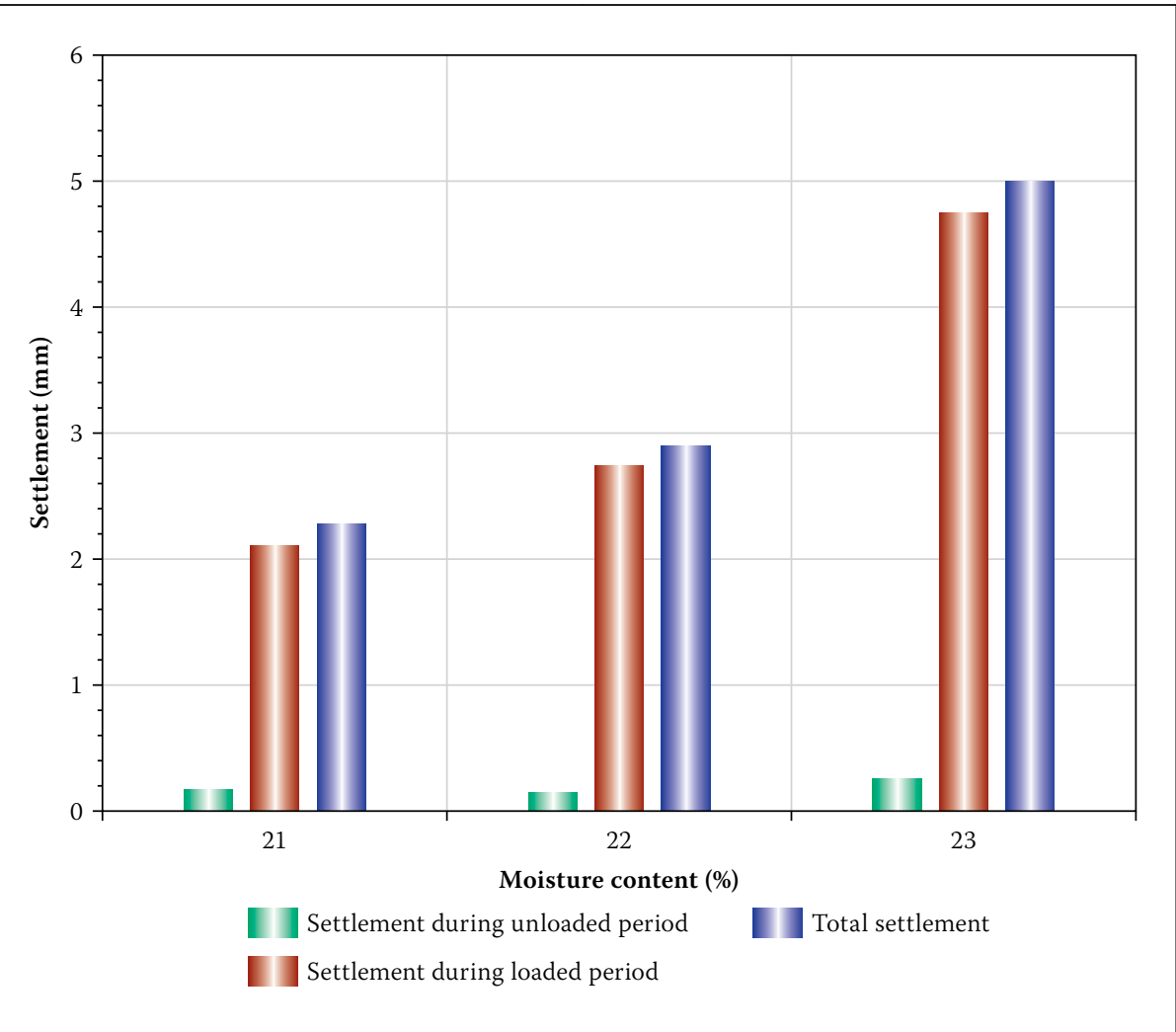

Figure 12: Total settlement during cyclic loading tests separated between self-weight and loading settlement

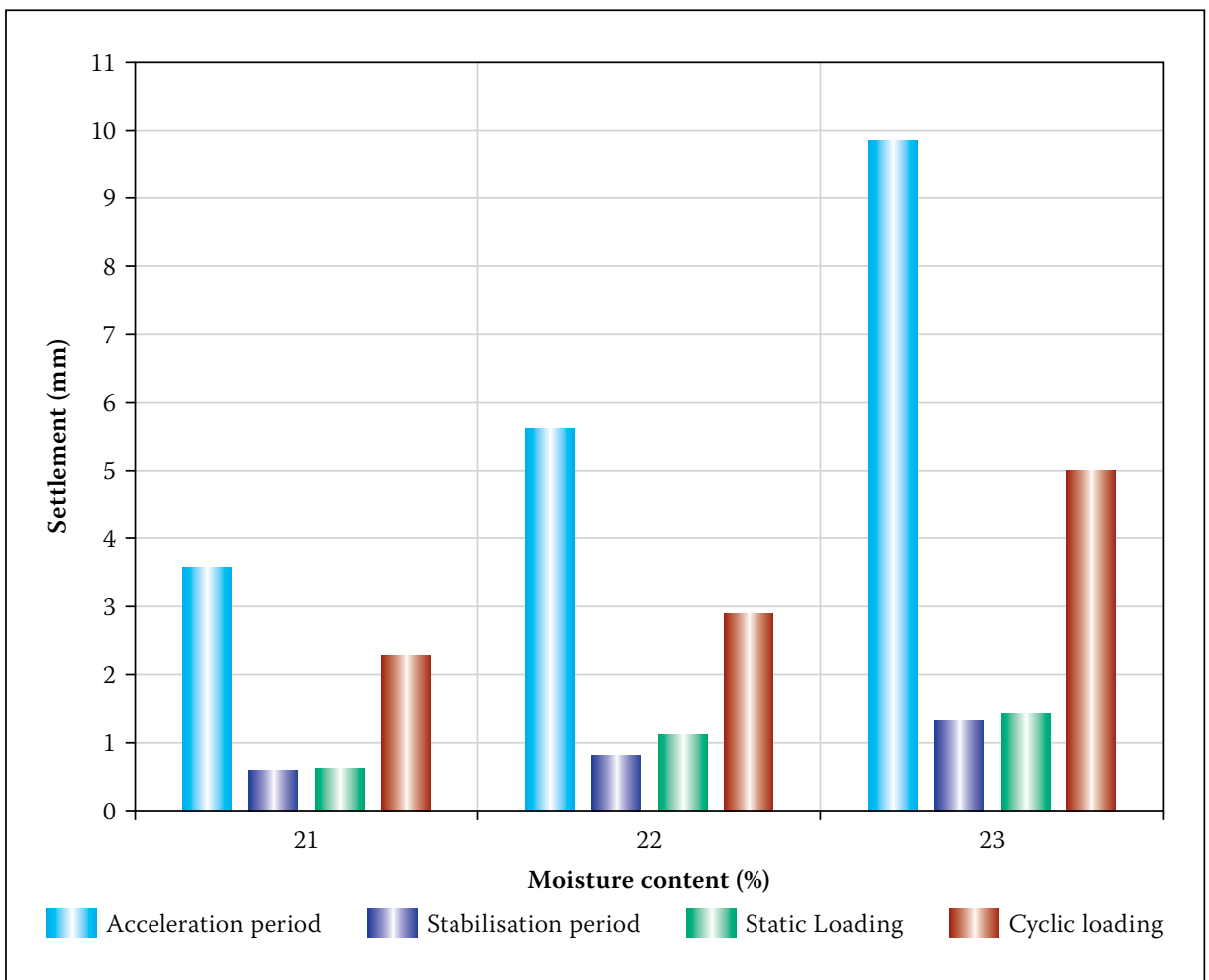

Figure 13: Final centrifuge testing settlement for each period during the tests for the same effective loaded time

content after three hours of loading. The settlement curve for the cyclic loading test at $23 \%$ moisture content, however, showed a $48 \%$ increase in settlement from the static loading settlement at $23 \%$ moisture content.

A settlement comparison between cyclic and static loading was done considering only the contact time during which the embankment was physically loaded. The settlement resulting from the cyclic loading was on average $67 \%$ higher than that of the static loading, when considering the loaded time. This can be attributed to continuous particle rearrangement during the cyclic loading process, as well as changes in the pore water pressures or suctions.
The settlement difference between static and cyclic loading with regard to loaded time increased by $8.7 \%$ for the $21 \%$ and $22 \%$ moisture content tests. However, a $51 \%$ increase in the settlement difference was observed for the $22 \%$ and $23 \%$ moisture content tests. This emphasises the effect that the moisture content of a soil has on its shear strength when the moisture increases above the moisture content corresponding to the air entry value and the level of saturation. At this level of saturation there is a definite decrease in pore water suctions, and hence the shear strength of the material, which can be expected to result in an increase in embankment settlement under loading.

The effect of moisture content on embankment settlement and performance is of great importance. Should an embankment moisture content increase to near saturation, small additional increases in the moisture content can result in instability, giving little warning. As the moisture content increases to the air entry value of the soil, the embankment settlement rapidly increases under cyclic loading, compared to static conditions. Railway embankment stability can therefore be expected to be affected detrimentally by effects of climate change which may result in moisture content increases. This is an aspect deserving further study.

\section{ACKNOWLEDGEMENTS}

Transnet Freight Rail is gratefully acknowledged for financial support to the Chair in Railway Engineering at the University of Pretoria. The laboratory staff of the Department of Civil Engineering at the University of Pretoria, as well as fellow students, are thanked for academic and technical support during the execution of the various laboratory tests.

\section{REFERENCES}

Blackall, T E 1952. A. M. Atterberg 1846-1916. Geotechnique, 3(1): 17-19.

Fredlund, D G \& Rahardjo, H 1993. Soil Mechanics for Unsaturated Soils. New York: Wiley Interscience. Gräbe, P J \& Clayton, C R I 2009. Effects of principal stress rotation on permanent deformation in rail track foundations. Journal of Geotechnical and Geoenvironmental Engineering, 135(4): 555-565.

Gunn, D A, Haslam, E, Kirkham, M, Chambers, J E,

Lacinska, A et al 2009. Moisture measurements in an end-tipped embankment: Application for studying long-term stability and ageing. Proceedings, 10th International Conference on Railway Engineering, 24-25 June, London.

Jacobsz, S W, Kearsley, E P \& Kock, J H L 2014. The geotechnical centrifuge facility at the University of 
Pretoria. In Springman, S M, Laue, J \& Seward, L. Physical Modelling in Geotechnics. London: Taylor \& Francis, 169-174.

Li, D, Hyslip, J, Sussmann, T \& Chrismer, S 2016 Railway Geotechnics. Boca Raton, F L: CRC Press/ Taylor and Francis.

Lourens, J P \& Maree, J S 1997. Rehabilitation design of high embankments and a coal line track formation. Proceedings, 6th International Heavy Haul Conference, 6-10 April, Cape Town, 1: 57- 75.

Lu, N \& Likos, W J 2004. Unsaturated Soil Mechanics. Hoboken, N J: Wiley.

Malvern Instruments Ltd 2012. Mastersizer 2000. Available at: www.malvern.com
McQueen, I S \& Miller, R F 1974. Approximating soil moisture characteristics from limited data: Empirical evidence and tentative model. Water Resources Research, 10(3): 521-527.

Rahardjo, H, Lee, T T, Leong, E C \& Rezaur, R B 2005. Response of a residual soil slope to rainfall. Canadian Geotechnical Journal, 42(2): 340-351.

Rahardjo, H, Lim, T T, Chang, M F \& Fredlund, D G 1995. Shear-strength characteristics of a residual soil. Canadian Geotechnical Journal, 32(1): 60-77.

Selig, E T \& Waters, J M 1994. Track Geotechnology and Substructure Management. London: Thomas Telford.

Taylor, R N 1995. Geotechnical Centrifuge Technologies, 1st ed. London: Blackie Academic \& Professional.
Transnet 2006. Specification for Railway Earthworks S410. Johannesburg: Transnet Ltd.

Tubey, L W \& Bulman, J N 1964. Micaceous soils: Methods of determining mica content and the use of routine tests in the evaluation of such soils. Proceedings, 2nd Conference of the Australian Road Research Board, Melbourne, 2, 880-901.

Turner, A K \& Schuster, R L 1996. Landslides Investigation and mitigation: National Research Council, Transportation Research Board Special Report 247. Washington: National Academy Press. Weinert, H H 1980. The Natural Road Construction Materials of Southern Africa. Cape Town: H \& R Academica. 